\title{
The Korean Version of Fear of COVID-19 Scale: Psychometric Validation in the Korean Population
}

\author{
Kyu-Sic Hwang ${ }^{1,2}$, Hye-Ji Choi ${ }^{1,2}$, Chan-Mo Yang ${ }^{1,2,6}$, Jeongwan Hong ${ }^{2,3}$, \\ Hye-Jin Lee ${ }^{4}$, Min-Cheol Park ${ }^{5}$, Seung-Ho Jang ${ }^{1,2,6} \bowtie$, and Sang-Yeol Lee $e^{1,2,6} \bowtie$ \\ ${ }^{1}$ Department of Psychiatry, Wonkwang University Hospital, Iksan, Republic of Korea \\ ${ }^{2}$ Korea Brain-Behavior Mental Health Institute, Jeonju, Republic of Korea \\ ${ }^{3}$ Department of Psychiatry, Iksan Hospital, Iksan, Republic of Korea \\ ${ }^{4}$ Department of Public Health, Wonkwang University Graduate School, Iksan, Republic of Korea \\ ${ }^{5}$ Department of Psychiatry, Shinsegae Hospital, Gimje, Republic of Korea \\ ${ }^{6}$ Department of Psychiatry, School of Medicine, Wonkwang University, Iksan, Republic of Korea
}

Objective Coronavirus disease 2019 (COVID-19) has psychological effects such as anxiety and depression as well as direct infection in people. The Fear of COVID-19 scale is a scale that can measure anxiety related to COVID-19 in a short time. The purpose of this study was to verify the reliability and validity the Korean version of Fear of COVID-19 scale (KF-COVID-19S).

Methods The data of total 186 normal adults and 17 patients were finally used for the statistical analysis. For internal consistency, Cronbach's $\alpha$ was calculated. For concurrent and discriminant validity, the correlations with the Hospital Anxiety and Depression scale (HADS), Patient Health Questionnaire-15 (PHQ-15), World Health Organization Quality of Life Assessment Instrument Brief Form (WHOQOLBREF) were analyzed. For construct validity, exploratory and confirmatory factor analysis were conducted.

Results Cronbach alpha was 0.88 . The two-factor model (factor 1: Physical fear, factor 2: Emotional fear) showed significantly positive correlations and appeared to be "good" fitness (CFI=0.906, IFI=0.907, NFI=0.902).

Conclusion The KF-COVID-19S can be a useful scale that can measure the physical and emotional fears associated with COVID-19 in a short time. Because the psychiatric patients are a more vulnerable group to the fear, it is thought that the KF-COVID-19S will help to determine the patient's level of anxiety and make a therapeutic plan for the underlying mental disorder.

Psychiatry Investig 2021;18(4):332-339

Key Words COVID-19, Coronavirus, Fear, Anxiety, COVID-19 fear.

\section{INTRODUCTION}

Coronavirus disease 2019 (COVID-19), which occurred in Wuhan, China in December 2019, is spreading across the world. As of October 12, 2020, COVID-19 has infected 24,704 people and killed 433 in Korea. ${ }^{1,2}$ The infectivity and propagation of COVID-19 have been found to be stronger than the exist-

Received: November 30, 2020 Revised: December 23, 2020

Accepted: January 7, 2021

$\bowtie$ Correspondence: Seung-Ho Jang, MD

Department of Psychiatry, School of Medicine, Wonkwang University, $895 \mathrm{Mu}-$ wang-ro, Iksan 54538, Republic of Korea

Tel: +82-63-859-1044, Fax: +82-63-857-1043, E-mail: sh-jang82@hanmail.net

$\triangle$ Correspondence: Sang-Yeol Lee, MD, PhD

Department of Psychiatry, School of Medicine, Wonkwang University, $895 \mathrm{Mu}$ wang-ro, Iksan 54538, Republic of Korea

Tel: +82-63-859-1044, Fax: +82-63-857-1043, E-mail: psysangyeol@hanmail.net (ac This is an Open Access article distributed under the terms of the Creative Commons Attribution Non-Commercial License (https://creativecommons.org/licenses/bync/4.0) which permits unrestricted non-commercial use, distribution, and reproduction in any medium, provided the original work is properly cited. ing SARS coronavirus and MERS coronavirus. As such, those residing in villages, cities, and countries struck with COVID-19 may experience significantly more anxiety, and in severe cases even fear, compared to pre-COVID-19 times. For example, according to a study from China, symptoms related to stress, anxiety, depression, and post-traumatic stress disorder (PTSD) increased after COVID-19, and did not decrease statistically. ${ }^{3}$ Another study also indicated that one in five students were experiencing mild anxiety. ${ }^{4}$

Therefore, people may suffer more from anxiety-related symptoms even if they do not have COVID-19 or other symptoms. ${ }^{5,6}$ This fear of infectious diseases can worsen existing mental disorders, and can lead to extreme anxiety responses. One study indicated that PTSD was caused by a strong fear of coming in contact with close family members or friends who were infected with COVID-19. ${ }^{7}$ Particularly, the possibility of exacerbating the fear of COVID-19 is increasing with the in- 
formation on news, messages, and social networking service regarding the rapid spread of the disease in regions. ${ }^{8}$

As such, an accurate assessment of the level of fear felt by the people is necessary, as COVID-19 is severely impacting human society at a global scale. The Fear of COVID-19 Scale, developed by Ahorsu et al., ${ }^{9}$ is an easy measure of fear, concerns and anxiety relating to COVID-19. Comprising seven items, the validity and reliability of the Fear of COVID-19 Scale were verified in the original study, and studies on adaptation and validation are ongoing in other countries. ${ }^{10,11}$ Through these assessments, it is possible to identify the level of influence of COVID-19 on mental health and daily life, and establish a national mental health policy relating to the disease. To this end, Korea requires an adaptation and validation study for the Fear of COVID-19 Scale.

This study developed the KF-COVID-19S, the Korean version of Fear of COVID-19 Scale, and analyzed its reliability and validity.

\section{METHODS}

\section{Development of the Korean version of the Fear of COVID-19 Scale (KF-COVID-19S)}

Prior to developing the KF-COVID-19S, the authors of this study obtained permission from the original authors of the Korean validation study to use the scale. Next, two psychiatrists and a clinical psychologist adapted the scale into Korean. Then, a Ph.D. holder from a U.S. university, fluent in both English and Korean, conducted the back-translation. Lastly, a psychiatrist and a clinical psychologist drafted the final version of KF-COVID-19S after discussion.

\section{Participants}

The study was conducted between June and November 2020. Participants are two groups (one for the normal adults and the other for the psychiatric patients). The normal participants were 207 adults aged 19 years or above, working at public institutions in Jeollabuk-do. A total of 186 responses were used for the research, after excluding 13 individuals with incomplete responses and 8 individuals with severe underlying medical conditions. The patient group included 23 individuals who visited the department of psychiatry and agreed to participate in the study. The study used data from 17 patients, excluding those experiencing a severe psychosis, with severe and clear underlying symptoms, and whose intellectual ability was questionable. This study was approved by the Institutional Review Board of Wonkwang University Hospital (No. WKUH 2020-05-040), and all the participants were given written informed consent.

\section{Measures}

The Fear of COVID-19 Scale (F-COVID-19S)

The original F-COVID-19S was developed by researchers from Hong Kong, Iran, the United Kingdom, and Sweden, and involved Iranian participants at the time of development. ${ }^{9}$ The F-COVID-19S consists of seven items measured on a 5-point Likert scale (1-5pts) with the responses "strongly disagree," "disagree," "neither agree nor disagree," "agree," and "strongly agree." The original study verified acceptable itemtotal correlation ( 0.47 to 0.56$)$, internal consistency $(\alpha=0.82)$, concurrent validity $(r=0.425, r=0.511)$ and strong factor loadings ( 0.66 to 0.74$)$.

\section{The Hospital Anxiety and Depression Scale (HADS)}

The Hospital Anxiety and Depression Scale (HADS) is a self-reported questionnaire developed to measure the levels of the most common symptoms of anxiety and depression of patients visiting hospitals in a short period of time. The HADS contains 14 questions, and is measured on a 4-point ( 0 to 3 points) scale. ${ }^{12}$ The seven odd-numbered questions relate to anxiety, and constitute a sub-scale for anxiety (HAD-Anxiety, HAD-A), and the seven even-numbered questions relate to depression, forming a sub-scale for depression (HAD-Depression, HAD-D). Higher scores on HADS indicate higher levels of anxiety and depression. ${ }^{12}$ Zigmond and Snaith ${ }^{12}$ presented the following cut-off points to differentiate between the normal group and the depressed/anxious groups: 0-7 points: normal, 8-10 points: Suspected anxious/depressed group, 11-21 points: Anxious/depressed group. The original study indicated that the correlation between the F-COVID-19S and the HADS was significant $(r=0.425, \mathrm{p}<0.0001$ for depression; $\mathrm{r}=$ $0.511, \mathrm{p}<0.001$ for anxiety). In this study, the internal consistency of HADS-A was 0.866 , and that of HADS-D was 0.812 , indicating "good" internal consistency.

\section{The Patient Health Questionnaire-15 (PHQ-15)}

The Patient Health Questionnaire-15 (PHQ-15) is a scale that is composed of 15 items related to physical symptoms. ${ }^{13}$ Each item is measured on a $0-2$ point scale, with the scores ranging from 0 to 30 . Interpretations of PHQ-15 scores proposed by the study by Kroenke et al. ${ }^{13}$ are as follows: $0-4$ points indicate "minimal," 5-9 points indicate "mild," 10-14 points indicate "moderate," and 15-30 points indicate "severe." This study used the version adapted by Han et al. ${ }^{14}$ In this study, the internal consistency of PHQ-15 was 0.858, indicating "good" internal consistency. 


\section{The World Health Organization Quality of Life Assessment} Instrument Brief Form (WHOQOL-BREF)

The World Health Organization Quality of Life Assessment Instrument Brief Form (WHOQOL-BREF) is a scale developed by the World Health Organization, Quality of Life Group. ${ }^{15}$ In this study, it was measured using the Korean Version of the WHOQOL-BREF, whose validity was assessed by Min et al. ${ }^{16}$ This scale is composed of four domains: physical health, mental, social, and life environment, and consists of 24 items. Each item is measured on a scale ranging from 1 to 5 points, with higher scores indicating higher quality of life. In this study, the internal consistency of WHOQOL-BREF was 0.921 , indicating "excellent" internal consistency.

\section{Statistical analysis}

First, frequency analysis was conducted on the descriptive statistics of the participants. This study calculated the means and standard deviations of each scale for the two groups and verified the differences in the means. Then, internal consistency was verified for reliability. Cronbach's alpha was used to verify internal consistency. To verify validity, this study used construct validity and concurrent validity. To verify construct validity, exploratory factor analysis (EFA) and confirmatory factor analysis (CFA) were utilized, and correlation analysis was conducted to verify concurrent validity. The maximum likelihood (ML) and oblique rotation (direct oblimin) methods were used for EFA. For CFA, comparative fit index (CFI), incremental fit index (IFI), and normed fit index (NFI) were used for the goodness of fit indicators. CFI, IFI, and NFI were all "acceptable" at values higher than 0.90 , indicating that the model has high goodness of fit..$^{17,18}$

\section{RESULTS}

\section{Demographic characteristics}

Table 1 shows the demographic characteristics and descriptive statistics of the sample. The average age of the normal adults was 39.19 years, with $55.9 \%$ men and $54.1 \%$ women; $39.2 \%$ were single and $56.5 \%$ were married. In terms of their education level, the largest subset $(74.0 \%)$ had 4 -year college degrees, followed by $13.0 \%$ who had 2-year college education and $13.0 \%$ who had only graduated high school.

Next, the average age of the psychiatric patients was 40.06 years, with $76.5 \%$ men and $23.5 \%$ women; $58.8 \%$ were single and $23.5 \%$ were married. In terms of their education level, the largest subset (41.1\%) had 4-year college degrees, followed by those who had graduated high school, at $29.4 \%$.

The differences for the age and gender between two groups were not statistically significant $\left[\mathrm{t}(101)=-0.294 ; \chi^{2}=2.70\right]$. However, the differences for the marital status and education
Table 1. Participants' demographic characteristics and descriptive statistics of measures

\begin{tabular}{lcccc}
\hline \multirow{2}{*}{ Variable } & \multicolumn{2}{c}{ Group } & Statistic \\
\cline { 2 - 3 } & $\begin{array}{c}\text { Normal adult } \\
(\mathrm{N}=186)\end{array}$ & $\begin{array}{c}\text { Patient } \\
(\mathrm{N}=17)\end{array}$ & $\mathrm{t}, \chi^{2}$ \\
\hline Age, years: mean \pm SD & $39.19 \pm 10.93$ & $40.06 \pm 17.81$ & -0.294 \\
Gender, Male: N (\%) & $104(55.9)$ & $13(76.5)$ & 2.70 \\
Marital status, N (\%) & & & $12.09^{*}$ \\
Unmarried & $73(39.2)$ & $10(58.8)$ & \\
Married & $105(56.5)$ & $4(23.5)$ & \\
Separated & $0(0.0)$ & $0(0.0)$ & \\
Divorced & $6(3.2)$ & $3(17.7)$ & \\
Lost & $2(1.1)$ & $0(0.0)$ & \\
Education level, N (\%) & & & $49.38^{\dagger}$ \\
Elementary school & $0(0.0)$ & $2(11.8)$ & \\
Middle school & $0(0.0)$ & $2(11.8)$ & \\
High school & $25(13.0)$ & $5(29.4)$ & \\
2-year college & $25(13.0)$ & $1(5.9)$ & \\
4-year college & $142(74.0)$ & $7(41.1)$ & \\
Measures, mean $\pm S D$ & & & \\
KF-COVID-19S & $18.90 \pm 5.16$ & $19.82 \pm 7.93$ & -0.668 \\
HADS-total & $10.81 \pm 7.05$ & $24.18 \pm 8.83$ & $-7.324^{\dagger}$ \\
HADS-anxiety & $4.64 \pm 3.63$ & $12.12 \pm 4.96$ & $-7.864^{\dagger}$ \\
HADS-depression & $6.17 \pm 3.96$ & $12.06 \pm 4.56$ & $-5.804^{\dagger}$ \\
PHQ-15 & $5.26 \pm 4.57$ & $12.65 \pm 6.25$ & $-6.164^{\dagger}$ \\
WHOQOL-BREF & $90.87 \pm 16.50$ & $64.65 \pm 12.89$ & $6.372^{\dagger}$ \\
\hline
\end{tabular}

${ }^{*} \mathrm{p}<0.01,{ }^{\dagger} \mathrm{p}<0.001$. N: number, SD: standard deviation, KF-COVID19S: Korean version of the fear of COVID-19 Scale, HADS: Hospital Anxiety and Depression Scale, PHQ-15: Patient Health Questionnaire-15, WHOQOL-BREF: World Health Organization Quality of Life Assessment Instrument Brief Form

levels between two groups were statistically significant $\left(\chi^{2}=\right.$ $12.09, \mathrm{p}<0.01$ for marital status; $\chi^{2}=49.38, \mathrm{p}<0.001$ for education level).

\section{Descriptive statistics for groups and total score of the KF-COVID-19S for percentile (\%)}

Table 1 also shows the mean and the mean difference testing results of the measures, by group. For the total scores of the KF-COVID-19S, the normal adult group had 18.90 pts and the patient group had 19.82 pts. In terms of the HADS-Total score, the mean score of normal adult group was 10.81 pts in the "normal" range, and the mean score of the patient group was 24.18 pts, in the "suspected anxious/depressed group." In terms of the PHQ-15 score, the mean score of normal adult group was 5.26 pts in the "mild" range, and the mean score of the patient group was 12.65 pts in the "moderate" range. As for the WHOQOL-BREF, the mean scores were 90.87 pts for the 
normal group and 64.65 pts for patient group. The results of descriptive statistics for each scale, by group, are as follows. The differences in the mean KF-COVID-19S scores of the two groups were not statistically significant $[t(201)=-0.668]$. However, the mean score differences of HADS-Total, HADS-A, HADS-D, PHQ-15, and WHOQOL-BREF were statistically significant $[\mathrm{t}(201)=-7.958$ for HADS-Total; $\mathrm{t}(201)=-8.746$ for HADS-A; $\mathrm{t}(201)=-5.804$ for HADS-D; $\mathrm{t}(201)=-6.164$ for PHQ$15 ; \mathrm{t}(201)=6.372$ for WHOQOL-BREF].

Table 2 shows the total score for each percentile using Zscore calculation. This study utilized Z-score calculation to analyze the individual scores according to the percentiles of the KF-COVID-19S data for normal adults. The total scores belonging to the $93 \%$ (the equivalent of 1.5 standard deviation) was 26.5 pts, and the total scores belonging to the $90 \%$ was 25.5 pts.

Table 2. Total score for each percentile using Z-score calculation $(\mathrm{N}=186)$

\begin{tabular}{cc}
\hline Percentile (\%) & Total score of the KF-COVID-19S (pts) \\
\hline 99 & 30.9 \\
98 & 29.5 \\
97 & 28.6 \\
96 & 27.9 \\
95 & 27.4 \\
94 & 26.9 \\
93 & 26.5 \\
92 & 26.2 \\
91 & 25.8 \\
90 & 25.5 \\
\hline
\end{tabular}

KF-COVID-19S: Korean version of the fear of COVID-19 Scale

\section{Internal consistency}

The Cronbach's alpha of the KF-COVID-19S adapted in this study was 0.88 , which can be interpreted as "good."

\section{Concurrent validity and discriminant validity}

Table 3 shows the results of the correlation analysis between KF-COVID-19S and HADS to verify the concurrent validity of the former. The correlations between KF-COVID-19S and HADS-total, HADS-Depression, and HADS-Anxiety were $\mathrm{r}=0.260, \mathrm{r}=0.175$, and $\mathrm{r}=0.314$, respectively, and were significant at 0.01 levels. The correlation with PHQ-15 was also analyzed; the results indicated $\mathrm{r}=0.266$, significant at 0.01 level. Furthermore, the correlation with WHOQOL-BREF was -0.224 , which was significant at the 0.01 level, indicating good discriminant validity.

\section{Construct validity}

Table 4 shows the results of the verification of construct validity in a table form. First, a two-factor structure was used to conduct EFA based on the results of the previous study. ${ }^{10}$ Kaiser-Meyer-Olkin and Bartlett's test of sphericity were used to confirm that factor analysis was possible $\left[\mathrm{KMO}=0.834 ; \chi^{2}\right.$ $(\mathrm{df}=21, \mathrm{n}=186)=658.753, \mathrm{p}<0.001] .{ }^{19}$ Maximum likelihood and Direct oblimin rotation were used to conduct EFA. The results indicated that the explaining power of the 2 -factor structure was $73.65 \%$. To verify the validity of the 2 -factor structure, CFA was conducted; the results indicated CFI= 0.906 , IFI $=0.907$, and $\mathrm{NFI}=0.902$, suggesting that the 2 -factor structure was acceptable.

Table 5 and Figure 1 show the two-factor structure of the KF-COVID-19S. The first extracted factor included items 3, 6, and 7 (No. 3: My hands become clammy when I think about

Table 3. Correlation analysis for the concurrent validity and discriminant validity $(\mathrm{N}=186)$

\begin{tabular}{|c|c|c|c|c|c|c|}
\hline & KF-COVID-19S & HADS-total & HADS-Depression & HADS-Anxiety & PHQ-15 & WHOQOL-BREF \\
\hline KF-COVID-19S & 1.00 & & & & & \\
\hline HADS-total & $0.260^{\dagger}$ & 1.00 & & & & \\
\hline HADS-depression & $0.175^{*}$ & $0.941^{\dagger}$ & 1.00 & & & \\
\hline HADS-anxiety & $0.314^{\dagger}$ & $0.940^{\dagger}$ & $0.770^{\dagger}$ & 1.00 & & \\
\hline PHQ-15 & $0.266^{\dagger}$ & $0.735^{\dagger}$ & $0.642^{\dagger}$ & $0.740^{\dagger}$ & 1.00 & \\
\hline WHOQOL-BREF & $-0.224^{\dagger}$ & $-0.721^{\dagger}$ & $-0.685^{\dagger}$ & $-0.671^{\dagger}$ & $-0.616^{\dagger}$ & 1.00 \\
\hline
\end{tabular}

${ }^{*} \mathrm{p}<0.05,{ }^{\dagger} \mathrm{p}<0.01$. KF-COVID-19S: Korean version of the fear of COVID-19 Scale, HADS: Hospital Anxiety and Depression Scale, PHQ-15: Patient Health Questionnaire-15, WHOQOL-BREF: World Health Organization Quality of Life Assessment Instrument Brief Form

Table 4. The goodness-of-fit for the 2-factor model by factor analysis solutions ( $\mathrm{N}=186)$

\begin{tabular}{cccrccc}
\hline Factor analysis solution & Cumulative \% of variance explained & $\chi^{2}$ & df & CFI & IFI & NFI \\
\hline EFA & $73.65 \%$ & 32.270 & 8 & N/A & N/A & N/A \\
CFA & & 82.730 & 13 & 0.906 & 0.907 & 0.902 \\
\hline
\end{tabular}

FAS: factor analysis solutions, EFA: exploratory factor analysis, CFA: confirmatory factor analysis, CFI: comparative fit index, IFI: incremental fit index, NFI: normed fit index 
Table 5. Factor loading, means $\pm S D s$, and item-total correlations of the two-factor model for the KF-COVID-19S (N=186)

\begin{tabular}{|c|c|c|c|c|c|c|}
\hline \multicolumn{4}{|c|}{ Item no. } & Factor loading & Mean \pm SD & Item-total correlation \\
\hline \multicolumn{7}{|l|}{ Factor 1: Physical fear } \\
\hline \multicolumn{4}{|c|}{ 03. My hands become clammy when I think about the coronavirus } & 0.727 & $2.30 \pm 1.00$ & $0.780^{*}$ \\
\hline \multicolumn{4}{|c|}{ 06. I cannot sleep because I'm worrying about getting the coronavirus } & 0.921 & $1.97 \pm 0.96$ & $0.802^{*}$ \\
\hline \multicolumn{4}{|c|}{ 07. My heart races or palpitates when I think about getting the coronavirus } & 0.867 & $2.24 \pm 1.08$ & $0.817^{*}$ \\
\hline \multicolumn{7}{|c|}{ Factor 2: Emotional fear } \\
\hline \multicolumn{4}{|c|}{ 01. I am most afraid of the coronavirus } & 0.729 & $3.34 \pm 0.96$ & $0.668^{*}$ \\
\hline \multicolumn{4}{|c|}{ 02. It makes me uncomfortable to think about the coronavirus } & 0.739 & $3.77 \pm 0.93$ & $0.611^{*}$ \\
\hline \multicolumn{4}{|c|}{ 04. I am afraid of losing my life because of the coronavirus } & 0.622 & $2.56 \pm 1.09$ & $0.809^{*}$ \\
\hline \multicolumn{4}{|c|}{$\begin{array}{l}\text { 05. When watching news and stories about the coronavirus on social media, } \\
\text { I become nervous or anxious }\end{array}$} & 0.620 & $2.81 \pm 1.08$ & $0.825^{*}$ \\
\hline \multicolumn{7}{|c|}{ *p<0.01. KF-COVID-19S: Korean version of the fear of COVID-19 Scale, SD: standard deviation } \\
\hline \multicolumn{7}{|c|}{$\begin{array}{l}\text { Emotional } \\
\text { fear }\end{array}$} \\
\hline \multirow{2}{*}{$\begin{array}{l}\text { 1. I am most afraid } \\
\text { of the coronavirus }\end{array}$} & 0.5 & & $\stackrel{0.81}{\longrightarrow}$ & & 0.89 & 0.89 \\
\hline & $\begin{array}{l}\text { 2. It makes me } \\
\text { uncomfortable to } \\
\text { think about the } \\
\text { coronavirus }\end{array}$ & $\begin{array}{l}\text { 4. I am afraid of } \\
\text { losing my life } \\
\text { because of the } \\
\text { coronavirus }\end{array}$ & $\begin{array}{l}\text { 5. When watching } \\
\text { on social media, } \\
\text { I become nervous } \\
\text { or anxious }\end{array}$ & $\begin{array}{l}\text { 3. My hands become } \\
\text { clammy when } \\
\mathrm{i} \text { think about the } \\
\text { coronavirus }\end{array}$ & $\begin{array}{l}\text { 6. I cannot sleep } \\
\text { because I'm } \\
\text { worrying about } \\
\text { getting the } \\
\text { coronavirus }\end{array}$ & $\begin{array}{l}\text { 7. My heart races or } \\
\text { palpitates when } \\
\text { I think about } \\
\text { getting the } \\
\text { coronavirus }\end{array}$ \\
\hline
\end{tabular}

Figure 1. Two-factor structure of KF-COVID-19S confirmatory factor analysis.

the coronavirus; No. 6: I cannot sleep because I'm worrying about getting the coronavirus; No. 7: My heart races or palpitates when I think about getting the coronavirus). This study named factor 1 as "Physical fear." The three items had factor loading values between 0.73 and 0.92 , which were high; the item-total correlation was also between 0.78 and 0.82 , which was also high. The second extracted factor included items 1 , 2, 4, and 5 (No. 1: I am most afraid of the coronavirus; No. 3: It makes me uncomfortable to think about the coronavirus; No. 4: I am afraid of losing my life because of the coronavirus; No. 5: When watching news and stories about the coronavirus on social media, I become nervous or anxious). This study named factor 2 as "Emotional fear." The four items had factor loading values between 0.62 and 0.74 , which were high; the item-total correlation was also between 0.61 and 0.83 , which was also high.

\section{DISCUSSION}

The purpose of this study was to adapt the Fear of COVID-19 scale into Korean, and verify its reliability and validity. The implications based on the results are as follows:
First, the differences were significant between the two groups in terms of marital status and education level. However, this is not a study to verify the mean difference between those two groups; it is a scale validation study with the normal group as a sample. There were no statistical differences between the mean total scores of the KF-COVID-19S of the normal adult group and patient group.

However, technically, the mean score of the patient group was high. In the other scales, which were HADS-total, HADSAnxiety, HADS-Depression, and PHQ-15, the mean scores of two groups had statistically significant differences, and the mean scores of patient group were higher than that of normal adult group. These results can be expected as the patients are psychiatric patients experiencing neurotic or psychotic symptoms. Furthermore, this study analyzed the individual scores according to percentiles for the total scores of KF-COVID19S; 93\% of KF-COVID-19S total score corresponding to $1.5 \mathrm{SD}$, which can be regarded as "Abnormal," was $26.5 \mathrm{pts}$, and $90 \%$ of total score considered to be "rare" was 25.5 pts. $^{20}$ These results suggest 26 points are the probable cut-off score, approximately equivalent to the $10 \%$ of normal adults sample. Therefore, if the KF-COVID-19S score is 26 pts or higher 
scores, the level of anxiety about COVID-19 can be considered high. However, as the cut-off scores calculated in this study is based on the sample of normal adults and z-score calculation, there are limitations to generalization that includes psychiatric patients with neurotic or psychotic symptoms. So the future study with a large number of psychiatric patients is needed for the frequency and prevalence analysis.

Next, in the reliability analysis, this study found that internal consistency was at reliable levels. In the original study and the one by Bitan et al., ${ }^{10}$ internal consistency was not studied. ${ }^{9,10}$ In the study by Sakib et al., ${ }^{11}$ Cronbach $\alpha$ was 0.871 , which is considered "Good." Cronbach's alpha in this study also corresponds to "Good," a statistically reliable level. ${ }^{21}$

Concurrent validity and discriminant validity were verified in the analysis of validity. Results of the concurrent validity verification showed significant positive correlations with HADS-total, HADS-Anxiety, HADS-Depression, and PHQ15. In the original study, the correlations between COVID-19S and HADS-Anxiety and HADS-Depression were significant (for depression, $\mathrm{r}=0.425, \mathrm{p}<0.001$; for anxiety, $\mathrm{r}=0.511, \mathrm{p}<$ 0.001). ${ }^{9}$ In the study by Sakib et al., ${ }^{11}$ PHQ-9 was used to measure depression. ${ }^{22}$ The correlation between COVID-19S and PHQ-9 was found to be significant [for PHQ-9 ( $r=0.406, \mathrm{p}<$ 0.001) $].{ }^{11}$ The study by Bitan et al. ${ }^{10}$ utilized the Depression, Anxiety and Stress Scale (DASS). ${ }^{23}$ Similarly, the correlation between DASS and COVID-19S was also significant (for anxiety, $\mathrm{r}=0.43, \mathrm{p}<0.001$; for depression, $\mathrm{r}=0.24$, $\mathrm{p}<0.001$ ). In summary, the results of existing studies indicated good concurrent validity between COVID-19S and scales measuring depression and anxiety. As in previous studies, this study also indicated a significant positive correlation between KF-COVID$19 S$ and the scales used to measure depression and anxiety, verifying concurrent validity. Additionally, this study also analyzed the correlation between KF-COVID-19S and WHOQOL-BREF to assess discriminant validity. The results indicated that the negative correlation was significant. This indicates the good discriminant validity of KF-COVID-19S.

The implications for the verification of construct validity are as follows: This study utilized the two-factor model, referencing the results of the study by Bitan et al. ${ }^{10}$ where the explaining power of the variance of the two-factor model was $65.76 \%$; in this study, the explaining power was higher at $73.65 \%$. Furthermore, this study also conducted a CFA on the two-factor model and found that the goodness of fit indices of CFI, IFI and NFI were all "acceptable."

Factor 1 was named "Physical fear" and, as the name suggests, it includes physical or physiological symptoms. These include symptoms such as insomnia, palpitation, and sweating. These physical or physiological symptoms may be experienced when the concerns around contracting COVID-19 are severe. One study found that panic attacks and generalized anxiety disorder symptoms, which could be diagnosed as mental disorders, could be experienced when these symptoms become extremely severe. ${ }^{24}$

Factor 2 was named "Emotional fear" and, like the name of the factor, it includes other expressions of fear. They contain adjectives such as "afraid," "uncomfortable," "nervous," and "anxious." According to a meta-analysis, the prevalence of anxiety caused by COVID-19 was $29.6 \%$, and the prevalence of depression was $33.7 \% .^{25}$ This indicates that COVID-19 causes significant psychological symptoms related to mental health as well as physical health. In particular, vulnerable groups such as psychiatric patients or people with mental health problems can easily experience a deterioration in their mental health; as such, they will need further attention and support in the COVID-19 era.

COVID-19 not only causes a direct consequence of infections, but also has a significant influence on society as a whole and at a global level. While the development of infection-preventing measures and medical treatments should be prioritized, the influence of COVID-19 on mental health should not be overlooked. ${ }^{26}$ In this regard, KF-COVID-19S is a useful scale that can quickly determine the degree of anxiety caused by COVID-19. As it is not a tool for the diagnosis of mental disorders, calculating an accurate cut-off score may not be very meaningful. However, as discussed in the results and discussion sections of this study, having scores of 26 pts or higher scores indicate that an individual has a higher degree of COVID-19-related anxiety compared to others. Particularly, patients with mental disorders who have neurotic or psychotic symptoms can be viewed as a group that is more vulnerable to COVID-19-related anxiety. The KF-COVID-19 can be used to determine the severity of COVID-19-related anxiety quickly in hospitals.

Lastly, the limitations and future research directions of this study are as follows. First, the normal adult sample was based on employees of public institutions at a specific region, indicating that the representativeness of the sample is not good. A follow-up, re-verification study, which involves randomly sampled participants, is required. In addition, when the number of normal adult participants is more than 1,000, re-verification of the cut-off score is required, and it is expected that the prevalence study can be conducted using this cut-off score. Second, the number of patient sample was small. Patients visiting the department of psychiatry are more vulnerable to anxiety, and the COVID-19-related stress of psychiatric patients is thought to be significant. Other studies have indicated that patients with mood disorders were more susceptible to COVID-19-related stress, which exacerbates the symptoms that they are experiencing. ${ }^{27}$ In this study, the KF-COVID-19S 
scores of the patients were higher than that of normal adults. In the future, follow-up studies on more psychiatric patients could help identify the psychological influences of COVID-19 on the psychiatric patients. Third, this study analyzed the correlations with general depression and anxiety-related scales; however, correlation analysis is needed to determine the correlations with scales that measure the direct negative effects of COVID-19. While there are no validation studies for the Korean versions, scales such as the Pandemic Stress Questionnaire (PSQ) and Coronavirus Anxiety Scale (CAS) have been developed abroad. ${ }^{28,29}$ Follow-up studies need to verify concurrent validity through correlation analyses between KFCOVID-19S, PSQ and CAS.

\section{Supplementary Materials}

The online-only Data Supplement is available with this article at https://doi.org/10.30773/pi.2020.0420.

\section{Acknowledgments}

This study was supported by Wonkwang University in 2020.

\section{Conflicts of Interest}

The authors have no potential conflicts of interest to disclose.

\section{Author Contributions}

Conceptualization: Sang-Yeol Lee, Seung-Ho Jang. Data curation: Sang-Yeol Lee, Seung-Ho Jang. Formal analysis: Jeong-Wan Hong, Hye-Jin Lee. Funding acquisition: Min-Cheol Park. Investigation: Kyu-Sic Hwang, Hye-Ji Choi. Methodology: Kyu-Sic Hwang, Chan-Mo Yang. Project administration: Sang-Yeol Lee, Seung-Ho Jang, Min-Cheol Park. Resources: Kyu-Sic Hwang, Hye-Ji Choi. Software: Kyu-Sic Hwang, Chan-Mo Yang. Supervision: Sang-Yeol Lee, Seung-Ho Jang, Min-Cheol Park. Validation: Kyu-Sic Hwang, Chan-Mo Yang. Visualization: Kyu-Sic Hwang, Jeong-Wan Hong, Hye-Jin Lee. Writing-original draft: Kyu-Sic Hwang, Hye-Jin Lee. Writing_review \& editing: Kyu-Sic Hwang, Jeong-Wan Hong.

\section{ORCID iDs}

Kyu-Sic Hwang

Hye-Ji Choi

Chan-Mo Yang

Jeong-Wan Hong

Hye-Jin Lee

Min-Cheol Park

Seung-Ho Jang

Sang-Yeol Lee

https://orcid.org/0000-0002-8997-8720 https://orcid.org/0000-0001-8280-3963 https://orcid.org/0000-0002-4959-7595 https://orcid.org/0000-0003-0458-6750 https://orcid.org/0000-0002-1039-9196 https://orcid.org/0000-0003-3508-8471 https://orcid.org/0000-0002-3479-0552 https://orcid.org/0000-0003-1828-9992

\section{REFERENCES}

1. Cases in Korea, Central Disaster Management Headquarters. Available at: http://ncov.mohw.go.kr/en/. Accessed October 12, 2020.

2. WHO Coronavirus disease (COVID-19) pandemic. Available at: https://www.who.int/emergencies/diseases/novel-coronavirus-2019. Accessed November 11, 2020.

3. Wang C, Pan R, Wan X, Tan Y, Xu L, McIntyre RS, et al. A longitudinal study on the mental health of general population during the COVID-19 epidemic in China. Brain Behav Immun 2020;87:40-48.

4. Cao W, Fang Z, Hou G, Han M, Xu X, Dong J, et al. The psychological impact of the COVID-19 epidemic on college students in China. Psychiatry Res 2020:112934.
5. Lin CY. Social reaction toward the 2019 novel coronavirus (COVID-19). Soc Health Behav 2020;3:1-2.

6. Colizzi M, Bortoletto R, Silvestri M, Mondini F, Puttini E, Cainelli C, et al. Medically unexplained symptoms in the times of COVID-19 pandemic: A case-report. Brain Behav Immun Health 2020;5:100073.

7. Sun L, Sun Z, Wu L, Zhu Z, Zhang F, Shang Z, et al. Prevalence and risk factors of acute posttraumatic stress symptoms during the COVID-19 outbreak in Wuhan, China. MedRxiv; 2020.

8. Qiu J, Shen B, Zhao M, Wang Z, Xie B, Xu Y. A nationwide survey of psychological distress among Chinese people in the COVID-19 epidemic: implications and policy recommendations. Gen Psychiatry 2020; 33:e100213.

9. Ahorsu DK, Lin CY, Imani V, Saffari M, Griffiths MD, Pakpour AH. The fear of COVID-19 scale: development and initial validation. Int J Ment Health Addict 2020:1-9. [Online ahead of print]

10. Bitan DT, Grossman-Giron A, Bloch Y, Mayer Y, Shiffman N, Mendlovic S. Fear of COVID-19 scale: Psychometric characteristics, reliability and validity in the Israeli population. Psychiatry Res 2020;289:113100.

11. Sakib N, Bhuiyan AKMI, Hossain S, Al Mamun F, Hosen I, Abdullah $\mathrm{AH}$, et al. Psychometric validation of the Bangla fear of COVID-19 scale: confirmatory factor analysis and Rasch analysis. Int J Ment Health Addict 2020:1-12. [Online ahead of print]

12. Zigmond AS, Snaith RP. The hospital anxiety and depression scale. Acta Psychiatr Scand 1983;67:361-370.

13. Kroenke K, Spitzer RL, Williams JB. The PHQ-15: validity of a new measure for evaluating the severity of somatic symptoms. Psychosom Med 2002;64:258-266.

14. Han C, Pae CU, Patkar AA, Masand PS, Kim KW, Joe SH, et al. Psychometric properties of the Patient Health Questionnaire-15 (PHQ-15) for measuring the somatic symptoms of psychiatric outpatients. Psychosomatics 2009;50:580-585.

15. Development of the World Health Organization WHOQOL-BREF quality of life assessment. The WHOQOL Group. Psychol Med 1998; 28:551-558.

16. Min SK, Lee CI, Kim KI, Suh SY, Kim DK. Development of Korean version of WHO Quality of Life Scale Abbreviated Version (WHOQOLBREF). J Korean Neuropsychiatr Assoc 2000;39:571-579.

17. Hu LT, Bentler PM. Cutoff criteria for fit indexes in covariance structure analysis: conventional criteria versus new alternatives. Struct Equat Modeling 1999;6:1-55.

18. Mulaik SA, James LR, Van Alstine J, Bennett N, Lind S, Stilwell CD. Evaluation of goodness-of-fit indices for structural equation models. Psychol Bull 1989;105:430-445.

19. Kaiser HF. An index of factorial simplicity. Psychometrika 1974;39:3136.

20. Binder LM, Iverson GL, Brooks BL. To err is human: "Abnormal" neuropsychological scores and variability are common in healthy adults. Arch Clin Neuropsychol 2009;24:31-46.

21. Bland JM, Altman DG. Statistics notes: Cronbach's alpha. BMJ 1997;314: 572.

22. Kroenke K, Spitzer RL, Williams JB. The PHQ-9: validity of a brief depression severity measure. J Gen Intern Med 2001;16:606-613.

23. Lovibond PF, Lovibond SH. The structure of negative emotional states: Comparison of the Depression Anxiety Stress Scales (DASS) with the Beck Depression and Anxiety Inventories. Behav Res Ther 1995;33:335343.

24. Islam MS, Ferdous MZ, Potenza MN. Panic and generalized anxiety during the COVID-19 pandemic among Bangladeshi people: an online pilot survey early in the outbreak. J Affect Disord 2020;276:30-37.

25. Bäuerle A, Teufel M, Musche V, Weismüller B, Kohler H, Hetkamp M, et al. Increased generalized anxiety, depression and distress during the COVID-19 pandemic: a cross-sectional study in Germany. J Public Health (Oxf) 2020;42:672-678. 
26. Pfefferbaum B, North CS. Mental health and the Covid-19 pandemic. N Engl J Med 2020;383:510-512.

27. Asmundson GJ, Paluszek MM, Landry CA, Rachor GS, McKay D, Taylor S. Do pre-existing anxiety-related and mood disorders differentially impact COVID-19 stress responses and coping? J Anxiety Disord 2020; 74:102271.
28. Kujawa A, Green H, Compas BE, Dickey L, Pegg S. Exposure to COVID-19 pandemic stress: associations with depression and anxiety in emerging adults in the United States. Depress Anxiety 2020;37:12801288.

29. Lee SA. Coronavirus Anxiety Scale: A brief mental health screener for COVID-19 related anxiety. Death Stud 2020;44:393-401. 


\section{SUPPLEMENTARY MATERIALS 1}

\section{The Korean Version of Fear of COVID-19 Scale (KF-COVID-19S)}

한국판 코로나-19불안 척도

아래의 질문들을 읽고 해당되는 응답에 대해 표시 바랍니다.

"나는 코로나바이러스감염증-19(코로나19)와 관련하여....."

\begin{tabular}{|c|c|c|c|c|c|c|}
\hline 번 호 & 문 항 & $\begin{array}{c}\text { 매우 } \\
\text { 동의하지 } \\
\text { 않는다 }\end{array}$ & $\begin{array}{l}\text { 동의하지 } \\
\text { 않는다 }\end{array}$ & $\begin{array}{l}\text { 동의도 } \\
\text { 반대도 } \\
\text { 아니다 }\end{array}$ & $\begin{array}{l}\text { 동의 } \\
\text { 한다 }\end{array}$ & $\begin{array}{c}\text { 매우 } \\
\text { 동의한다 }\end{array}$ \\
\hline 1 & 코로나19를 가장 무서워한다. & (1) & (2) & (3) & (4) & (5) \\
\hline 2 & 코로나19를 생각하면 마음이 불편하다. & (1) & (2) & (3) & (4) & (5) \\
\hline 3 & 코로나19를 생각하면 손에 땀이 날정도다. & (1) & (2) & (3) & (4) & (5) \\
\hline 4 & 코로나19때문에 목숨을 잃을까봐 두렵다. & (1) & (2) & (3) & (4) & (5) \\
\hline 5 & $\begin{array}{l}\text { 소셜 미디어에서 코로나 } 19 \text { 뉴스와 } \\
\text { 이야기를 볼 때 초조해지거나 불안해진다. }\end{array}$ & (1) & (2) & (3) & (4) & (5) \\
\hline 6 & 코로나19에 걸릴까봐 걱정이 되어서 잠을 잘 수가 없다. & (1) & (2) & (3) & (4) & (5) \\
\hline 7 & 코로나 19 걸리는 생각을 하면 심장이 뛰거나 두근거린다. & (1) & (2) & (3) & (4) & (5) \\
\hline
\end{tabular}

